\title{
Morphophysiological changes in Malpighian tubule cells during Myrmeleon uniformis development (Neuroptera, Myrmeleontidae)
}

\author{
C.A. Pacheco and T.L. Silva \\ 2011. Instituto de Biociências, Letras e Ciências Exatas, \\ Universidade Estadual Paulista "Júlio de Mesquita Filho", \\ São José do Rio Preto, SP, Brasil \\ Doctoral thesis. Orienting Prof.: M.T.V. de Azeredo-Oliveira \\ DOI http://dx.doi.org/10.4238/2013.June.27.1 \\ Corresponding author: T.L. Silva \\ E-mail: lucenabio@hotmail.com
}

The land arthropod secretory system is formed by structures called Malpighian tubules. These tubules are extremely important in insects because they maintain osmoregulation. They are located in the body cavity and are either free or inserted in the rectum wall, forming an arrangement known as the cryptonephridial system. The Malpighian tubules may have morphologically different regions, with each one formed by a specific cell type. Secondary specializations are found in Malpighian tubules, in which a region of the tube may be involved in the production of some substances, while other regions are responsible for other products. This is what occurs in cases of certain species of the order Neuroptera, which utilize tubules to produce cocoon silk thread during the last larval stage. The cells of Malpighian tubules of Myrmeleon uniformis undergo endoreduplication during the species' larval development and become highly polyploid in the last larval stage. However, this increased ploidy is not established in all parts of the tubule but only in regions selected, which suggests that only some parts of the tubule undergo these modifications for silk production while the other regions of the tubule are still used for basic functions of osmoregulation. In this study, the following cytochemical techniques were used: toluidine blue, xylidine ponceau, silver impregnation, along with the molecular cytogenetic technique termed fluorescence in situ hybridization. These techniques allowed us to see alterations at both the cellular and cytoplasmic level. These alterations provided evidence of increased synthesis of the substances secreted by specific cell types during the course of larval development. Ultrastructural analyses were also performed in both larval and adult stages, and these analyses confirmed the existence of 2 cell types present in the Malpighian tubules.

Key words: Malpighian tubules; Cryptonephridial system; Endoreduplication; Polyploidy; Neuroptera; Myrmeleon uniformis 